\title{
Velhice e a relação com idosos: 0 olhar de adolescentes do ensino fundamental
}

\author{
Agingandrelationwiththe ddaly: the vienpairt of enertaryschod teens
}

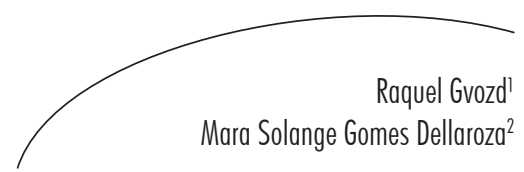

Resumo

Objetivo: analisar a percepção de estudantes da $\sigma^{a}$ série de uma escola pública do norte do Paraná sobre a velhice. Metodologia: realizou-se estudo individuado, observacional e transversal; a coleta de dados ocorreu através da aplicação de questionário na escola. Resultados: 87\% adolescentes afirmaram já ter convivido com pessoas idosas (70,7\%); $88,5 \%$ consideraram esse convívio positivo e $11,5 \%$ avaliaram de forma indiferente, nenhum dos participantes considerou a qualidade do convívio com a pessoa idosa como negativa. Muitos adolescentes possuem percepções positivas sobre o envelhecer, percepções negativas existem, mas com menor frequência. A percepção sobre envelhecimento foi analisada através da associação com as variáveis: sexo, escolaridade do chefe da família e convívio com idosos. Sexo e o convívio com idosos podem estar associados a algumas concepções, não sendo possível, entretanto, comprovar uma tendência positiva ou negativa. Conclusão: espera-se com este estudo contribuir para que o educador possa realizar uma abordagem sobre envelhecimento baseada em conceitos, percepções e vivências existentes no universo dos adolescentes e assim leve para os jovens a construção ou fortalecimento de concepções positivas sobre a velhice.

\section{Abstract}

Objective: Analyze the viewpoint of 6th grade students in a public school in northern Paraná state about aging. Methods: a sectional study was conducted, individual, observational, transverse; data was collected through self-administered questionnaires at school. Results: $87 \%$ of the teenagers reported having already lived with elderly people $(70,7 \%) ; 88,5 \%$ considered it positive and $11,5 \%$ evaluated in a different way, none of the participants considered as negative the quality of living with elderly people. Many young people have positive perceptions about aging and that negative perceptions exist, but these are less frequently. The notice about aging was analyzed carrying out
Palavras-chave:

Relação entre Gerações.

Envelhecimento. Adolescente.

Key words: Intergenerational Relations. Aging. Adolescent.

\footnotetext{
Gerência dos Serviços de Enfermagem, Universidade Estadual de Londrina. Londrina, PR, Brasil.

2 Departamento de Enfermagem, Universidade Estadual de Londrina. Londrina, PR, Brasil. 
the association with those variables: sex, scholarship of the head of the family and the living with elderly people. Gender and coping with elderly may be associated with some viewpoits, not being possible, however, to provide positive or negative trends. Conclusion: we hope this study can help the educator make an approach on aging based on concepts, perceptions and experiences in the universe of adolescent and young people, building or strengthening positive conceptions about aging.

\section{INTRODUÇÃO}

$\mathrm{Na}$ sociedade moderna, em que jovens estão cada vez mais desvinculados dos idosos, surge a preocupação em resgatar laços entre as duas gerações, aliando a sabedoria e experiência de vida dos idosos com conhecimentos da vida moderna dos jovens.

A geração mais jovem também transmite aos idosos valores e conhecimentos do mundo atual, podendo haver troca de saberes e experiências que permitam maior interação entre essas gerações. ${ }^{1}$ As trocas intergeracionais não devem ser limitadas à família e aos programas e políticas governamentais, mas devem ser expandidas às instituições privadas e a outras representações da sociedade. ${ }^{2}$ porque

por meio de experiências relativas às oficinas propostas no ensino fundamental e médio, da avaliação $e$ intervenção pertinentes às relações em sala de aula, possa acontecer à construção de relações humanas qualificadas, que resultem em ações comunitárias significativas, promovendo, assim, o desenvolvimento ético e a saúde física e mental dos escolares, da escola el ou das redes de ensino. ${ }^{3}$

A escola poderá oferecer práticas escolares de encontros que contemplem a integração de gerações, facilitando a tolerância e a identificação positiva com os idosos, ${ }^{3}$ havendo necessidade de conscientização dos educadores, pois são eles que possuem papel fundamental para intermediar tais ações.

No caminho em direção à fase da velhice, em decorrência de inúmeros fatores culturais contemporâneos, os contatos sociais tendem a rarear, isto é, assiste-se a um progressivo esvaziamento de papéis, fato que determina no idoso um crescente isolamento ou recolhimento ao espaço doméstico. ${ }^{1}$ Os idosos precisam ser estimulados a interagir produtivamente com todas as faixas etárias. ${ }^{2}$ É o idoso quem mais poderá ajudar na quebra dos preconceitos existentes, pois poderá dizer sobre a adaptação necessária frente às mudanças físicas e sociais da adolescência e do processo de envelhecimento.

O idoso é visto pelos mais jovens como alguém sem expectativas de vida, sem maiores oportunidades na sociedade e que acaba sendo alienado ao que lhe é proporcionado, sendo muitas vezes ligado à visão de incapacidade física e doença. Levando em consideração que a relação intergeracional entre adolescentes e idosos se faz necessária, o presente estudo teve como objetivo analisar a percepção de estudantes da $\sigma^{a}$ série de uma escola pública do norte do Paraná sobre a velhice.

\section{MATERIAIS E MÉTODOS}

Estudo individuado, observacional e transversal, desenvolvido com adolescentes de uma escola estadual da região norte do Paraná, recrutados através da lista fornecida pela escola.

O estudo foi aprovado pelo Comitê de Pesquisa da Universidade Estadual de Londrina, parecer $n^{\circ}$ 232/08, com registro no Sistema Nacional de Informação sobre Ética em Pesquisa CAAE no 0230.0.268.000-08.

Os questionários foram aplicados aos adolescentes na escola e a pesquisadora responsável explicou sobre os objetivos da pesquisa e o direito de participar ou não. Os pais e responsáveis foram contatados em reunião pedagógica, na qual receberam todas as 
informações referentes à pesquisa e assinaram o termo de consentimento. Todos os adolescentes cujos pais assinaram o termo participaram da pesquisa; em seguida, procedeu-se à coleta de dados. Foram consideradas perdas os casos de ausência do termo de consentimento assinado pelos pais ou responsável.

Os questionários foram aplicados aos alunos matriculados na $\sigma^{a}$ série do ensino fundamental em dezembro de 2008 e março de 2009, pela pesquisadora principal, a saber: a primeira parte continha a caracterização da população e o grau de escolaridade do chefe da família. A segunda parte foi de caracterização do convívio dos adolescentes com idosos, além de investigar se eles já refletiram sobre seu próprio envelhecimento.
Também nesta parte foi analisada a visão que os adolescentes possuem sobre o envelhecimento nas diferentes situações que abrangem a velhice. Esta seção do questionário baseou-se em instrumento de inventário Sheppard para avaliação de atitudes em relação à velhice, adaptado e validado pela professora Anita L. Néri para o português. ${ }^{4} \mathrm{E}$ na terceira parte, os adolescentes escolheram diferentes adjetivos para caracterizar o idoso, sendo possível analisar a visão deles acerca do envelhecimento, baseado em diferencial semântico de Osgood, conforme proposto por Neri. ${ }^{4}$

Para melhor entendimento dos resultados apresentados, optamos por apresentar parte dos instrumentos utilizados.

Quadro 1 - Parte do Instrumento de avaliação da percepção de adolescentes sobre envelhecimento.

\begin{tabular}{|c|c|c|c|c|c|}
\hline & 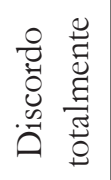 & 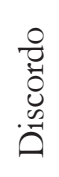 & 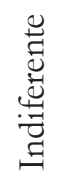 & 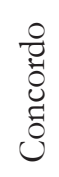 & 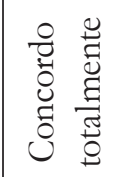 \\
\hline 1. É na juventude que se pode esperar o máximo de satisfação na vida & & & & & \\
\hline 2. Ao pensar no meu envelhecimento eu me sinto apreensivo & & & & & \\
\hline
\end{tabular}

Fonte: Inventário Sheppard, adaptado para o português por Anita Liberalesso Neri (1986).

Quadro 2 - Parte do Instrumento que avaliou a percepção dos adolescentes sobre o envelhecimento através de adjetivos.

\begin{tabular}{|c|c|c|c|c|c|c|c|c|}
\hline \multicolumn{7}{c|}{ PARA VOCÊ O VELHO É: } \\
\hline & 1 & 2 & 3 & 4 & 5 & 6 & 7 & \\
\hline Construtivo & & & & & & & & Destrutivo \\
\hline Esperançoso & & & & & & & & Desesperado \\
\hline
\end{tabular}

Fonte: Diferencial Semântico de Osgood, conforme proposto por Neri (1991).

As respostas dos adolescentes foram analisadas segundo associação com as variáveis sexo, idade, grau de escolaridade do chefe da família, realização de atividades na escola e convívio anterior com idosos. Os dados coletados foram previamente tabulados, digitados no programa Excell. 


\section{RESULTADOS}

As características sociodemográficas dos 123 adolescentes pesquisados foram: idade entre 11 e 16 anos, com a média de 12,13 e desvio padrão de 1,024; a maioria dos adolescentes tinha de $11(26,8 \%)$ a 12 anos (48\%). Quanto ao sexo, $61,8 \%$ eram meninas e $38,3 \%$ meninos. No que diz respeito a escolaridade do chefe da família, 21,1\% tinham até a $4^{a}$ série do ensino fundamental, $26 \%$ estudaram da $5^{a}$ a $8^{a}$ séries e $32,5 \%$, o ensino médio.

Oitenta e sete participantes afirmaram já ter convivido com pessoas idosas. Destes, 77 $(88,5 \%)$ consideraram esse convívio positivo e 10 $(11,5 \%)$ avaliaram de forma indiferente. Nenhum considerou a qualidade do convívio com a pessoa idosa como negativa; 69,9\% referiram já ter pensado em seu envelhecimento.

Em 35 dos 40 itens avaliados, mais de 50\% dos adolescentes entrevistados expressaram concepções positivas sobre a velhice. Em um único item, mais de 50\% dos adolescentes sinalizaram um aspecto negativo no envelhecer, considerando o idoso como dependente.

Apresentaremos as análises das repostas do questionário nas quais as variáveis analisadas demonstraram resultados estatisticamente significativos. No instrumento de avaliação, havia uma questão que interrogava os adolescentes sobre o enfrentamento da própria morte, e que apresentou significância para algumas variáveis analisadas (tabela 1).

Tabela 1 - Distribuição das respostas dos adolescentes referentes a dificuldade de enfrentar a ideia da própria morte para as variáveis: sexo, convívio anterior com idosos e participação em atividades na escola. Londrina, PR, 2009

\begin{tabular}{|c|c|c|c|c|c|}
\hline \multirow{3}{*}{ Variáveis } & \multicolumn{4}{|c|}{$\begin{array}{c}\text { É sempre difícil enfrentar a ideia de } \\
\text { nossa morte }\end{array}$} & \multirow[b]{3}{*}{ Teste* Significância } \\
\hline & \multicolumn{2}{|c|}{ Discordo } & \multicolumn{2}{|c|}{ Concordo } & \\
\hline & $\mathrm{n}$ & $\%$ & $\mathrm{n}$ & $\%$ & \\
\hline \multicolumn{6}{|c|}{ ATIVIDADES NA ESCOLA } \\
\hline Sim & 17 & 23,6 & 55 & 76,4 & \\
\hline Não & 16 & 44,4 & 20 & 55,6 & 0,045 \\
\hline \multicolumn{6}{|l|}{ SEXO } \\
\hline Masculino & 18 & 42,9 & 24 & 57,1 & \\
\hline Feminino & 15 & 22,7 & 51 & 77,3 & 0,033 \\
\hline \multicolumn{6}{|c|}{ CONVÍVIO COM IDOSOS } \\
\hline Sim & 16 & 21,1 & 60 & 78,9 & \\
\hline Não & 17 & 53,1 & 15 & 46,9 & 0,001 \\
\hline
\end{tabular}

* Teste exato de Fisher

O convívio com idosos influenciou positivamente na percepção referente ao tema sobre companheirismo na velhice. Os adolescentes que convivem com idosos relataram com maior frequência concordar com a afirmação que "é possível continuar tendo companheirismo na velhice" $(\mathrm{p}=0,018)$. Novas pesquisas precisam ser realizadas para explicar tais achados.
A percepção sobre envelhecimento foi analisada realizando associação com as variáveis: sexo, escolaridade do chefe da família e convívio com idosos. A variável escolaridade do chefe da família não apresentou significância estatística para os aspectos analisados. 
Tabela 2. Distribuição das opiniões de adolescentes quanto a concepções negativas e positivas frente ao envelhecimento e sua associação com sexo. Londrina, PR, 2009

\begin{tabular}{lcccccccccc}
\hline & \multicolumn{1}{c}{ MASCULINO } & \multicolumn{7}{c}{ FEMININO } \\
\hline CONCEPÇÃO & \multicolumn{1}{c}{ Positivo } & \multicolumn{2}{c}{ Negativo } & \multicolumn{2}{c}{ Positivo } & \multicolumn{2}{c}{ Negativo } & CONCEPÇÃO & Teste \\
POSITIVA & $\mathrm{n}$ & $\%$ & $\mathrm{n}$ & $\%$ & $\mathrm{n}$ & $\%$ & $\mathrm{n}$ & $\%$ & NEGATIVA & Estatístico* \\
\hline Esperançoso & 23 & 69,7 & 10 & 30,3 & 61 & 91,0 & 06 & 9,0 & Desesperado & 0,009 \\
Humilde & 20 & 57,1 & 15 & 42,9 & 54 & 83,1 & 11 & 16,9 & Arrogante & 0,008 \\
Alegre & 27 & 73,0 & 10 & 27,0 & 55 & 88,7 & 07 & 11,3 & Triste & 0,056 \\
Saudável & 21 & 58,3 & 15 & 41,7 & 45 & 78,9 & 12 & 21,1 & Doente & 0,038 \\
Independente & 09 & 27,3 & 24 & 72,7 & 28 & 49,1 & 29 & 50,9 & Dependente & 0,048 \\
Interessante & 24 & 68,6 & 11 & 31,4 & 55 & 93,2 & 04 & 6,8 & Desinteressante & 0,003 \\
Valorizado & 24 & 63,2 & 14 & 36,8 & 48 & 81,4 & 11 & 18,6 & Desvalorizado & 0,058 \\
Progressista & 13 & 50,0 & 13 & 50,0 & 35 & 89,7 & 04 & 10,3 & Retrógrado & 0,001 \\
\hline
\end{tabular}

* Teste exato de Fisher

O sexo teve associação com oito $(20 \%)$ das 40 concepções analisadas. As meninas em todos os itens sinalizados na tabela 2 apresentaram maior frequência de concepções positivas, tais como: o idoso é esperançoso, humilde, saudável, interessante, valorizado, progressista.

TABELA 3 - Distribuição das opiniões de adolescentes quanto a concepções negativas e positivas frente ao envelhecimento e sua associação com o relato de convívio com idosos. Londrina, PR, 2009

\begin{tabular}{|c|c|c|c|c|c|c|c|c|c|c|}
\hline \multirow[b]{4}{*}{$\begin{array}{l}\text { CONCEPÇÃO } \\
\text { POSITIVA }\end{array}$} & \multicolumn{8}{|c|}{ CONVÍVIO COM IDOSOS } & & \\
\hline & \multicolumn{4}{|c|}{ SIM } & \multicolumn{4}{|c|}{ NÃO } & & \\
\hline & \multicolumn{2}{|c|}{ Positivo } & \multicolumn{2}{|c|}{ Negativo } & \multicolumn{2}{|c|}{ Positivo } & \multicolumn{2}{|c|}{ Negativo } & \multirow[b]{2}{*}{$\begin{array}{c}\text { CONCEPÇÃO } \\
\text { NEGATIVA }\end{array}$} & \multirow[b]{2}{*}{$\begin{array}{c}\text { Teste } \\
\text { Estatístico* }\end{array}$} \\
\hline & $\mathrm{n}$ & $\%$ & $\mathrm{n}$ & $\%$ & $\mathrm{n}$ & $\%$ & $\mathrm{n}$ & $\%$ & & \\
\hline Sociável & 54 & 83,1 & 11 & 16,9 & 19 & 61,3 & 12 & 38,7 & Isolado & 0,024 \\
\hline Atualizado & 43 & 74,1 & 15 & 25,9 & 13 & 48,1 & 14 & 51,9 & Ultrapassado & 0,027 \\
\hline Atento & 45 & 66,2 & 23 & 33,8 & 07 & 31,8 & 15 & 68,2 & Distraído & 0,006 \\
\hline Seguro & 59 & 73,8 & 21 & 26,3 & 12 & 50,0 & 12 & 50,0 & Inseguro & 0,044 \\
\hline Saudável & 53 & 79,1 & 14 & 20,9 & 13 & 50,0 & 13 & 50,0 & Doente & 0,010 \\
\hline Alerto & 50 & 73,5 & 18 & 26,5 & 10 & 45,5 & 12 & 54,5 & Sem energia & 0,020 \\
\hline Forte & 43 & 70,5 & 18 & 29,5 & 07 & 36,8 & 12 & 63,2 & Fraco & 0,014 \\
\hline
\end{tabular}

* Teste exato de Fisher 
O convívio com idosos apresentou associação estatisticamente significativa com sete $(17,5 \%)$ dos 40 conceitos avaliados. Em todos estes, os adolescentes que convivem com idosos expressaram concepções positivas, entre as quais: o idoso é sociável, atualizado, atento, seguro, saudável, com energia e forte.

Referiram ter participado de atividades sobre o tema na escola $65 \%$ dos entrevistados. Dos 55 estudantes matriculados em 2008 que responderam ao questionário, 53 (96,4\%) afirmaram ter participado de atividades na escola. Para os matriculados em 2009, 27 dos 68 adolescentes afirmaram ter participado das atividades, equivalendo a $39,7 \%$ destes.

Os adolescentes da $6^{a}$ série participaram de dinâmicas na escola relacionadas a situações e dificuldades vividas pelos idosos. As dinâmicas foram organizadas pelo Grupo de Estudo sobre Envelhecimento da Universidade Estadual de Londrina em parceria com os professores da escola.

\section{DISCUSSÃO}

Quanto aos itens avaliados no primeiro quadro apresentado no método, somente o item 7, que diz: "é sempre difícil enfrentar a ideia de nossa morte", teve significância estatística. Quanto a esta percepção de adolescentes sobre a morte, não foram encontrados trabalhos publicados sobre o tema, o que nos impede de aprofundar a análise dos resultados encontrados.

Estudos realizados com estudantes de graduação da área da saúde reforçam a importância de refletir sobre o morrer. A análise das entrevistas mostrou que todas as experiências tocaram, de certa maneira, cada um dos investigados, reforçando que cada óbito é uma experiência única e exclusiva. ${ }^{5}$

O estudo demonstrou, ainda, que os acadêmicos de enfermagem percebem a morte como tabu; um assunto que não é falado, discutido, tanto na sociedade como na graduação. Esta realidade, ao ser percebida como algo misterioso, gerador de medo, angústia e ansiedade, nos passa a ideia de que a morte virou realmente um tabu. A morte é capaz de gerar muitos pensamentos dirigidos à emoção, até mesmo quando os indivíduos são levados apenas a refletir sobre a mesma. ${ }^{5}$

Os acadêmicos entrevistados têm grande dificuldade para reconhecer seus próprios limites. Para alguns, a morte é um processo natural, que atinge a todos, e os entrevistados dizem ter vivenciado tal fenômeno com normalidade, enquanto outros relataram dificuldade para superar tal acontecimento, mostrando em suas falas os sentimentos de ansiedade, culpa, impotência e angústia gerados pela experiência. ${ }^{5}$

Em investigação realizada com dez alunos regularmente matriculados entre o terceiro e sexto ano do curso de Medicina da PUC-RS, percebe-se a importância de estudar esse tema, já que a compreensão de jovens sobre o morrer pode influenciar suas opções de como viver. ${ }^{6}$

Quanto à influência do convívio com idosos na percepção dos adolescentes, os resultados obtidos em nosso estudo concordam com estudo realizado com 277 estudantes dos cursos de Pedagogia, Educação Física, Medicina e Enfermagem, verificando que os alunos que relataram conviver com idosos pontuaram mais favoravelmente nos itens relacionados a estereótipos de velhice. ${ }^{7}$ Esses dados sugerem que a convivência intergeracional seja importante fonte de aprendizagem de atitudes em relação aos idosos e que possa predispor favoravelmente as pessoas em relação à velhice.

A vivência em família é uma experiência rica em oportunidades para a construção de diferentes relacionamentos pessoais, no sentido de que as experiências falam ao mesmo tempo das necessidades, dificuldades, capacidades e incapacidades relacionais de todos e de cada um. ${ }^{8}$

Estudo investigativo referente aos dados sociodemográficos e clínicos de idosos de uma Unidade Básica de Saúde da Família de Fortaleza - CE revelou que 44,9\% dos idosos estudados moravam em domicílio multigeracional, 
prevalecendo os domicílios com três gerações (presença de filhos e netos); 43,5\% moravam com filhos e/ou cônjuge e 11,7\% sozinhos, ${ }^{9}$ o que comprova a importância de uma abordagem significativa com a população mais jovem referente ao convívio com idosos. Em nosso estudo, $87 \%$ dos adolescentes relataram ter convivido com pessoa idosa, mas não foram encontrados mais estudos referentes ao tema que possam discutir tal informação.

A presença dos filhos e netos é muito significativa na vida da pessoa idosa, porém mais importante é a manutenção de sua independência e autonomia..$^{10} \mathrm{O}$ envelhecimento desencadeia sentimentos de insegurança, medo e dúvidas - assim, vemos a importância de incentivar o convívio entre idosos e crianças para uma troca de saberes, em que ambos se beneficiam.

O envelhecimento está associado a questões familiares, sendo um processo vivido com mais segurança, confiança e tranquilidade quando o indivíduo possui laços de amizade e de parentesco. ${ }^{10}$ Além disso, a convivência entre pessoas de diferentes faixas etárias é fundamental para a continuidade do processo de vínculo intergeracional. Desta forma, o convívio intergeracional no contexto da família parece ser benéfico a jovens e idosos.

Não foi possível separar os adolescentes que participaram das dinâmicas para a realização das análises, pois o $n$ não permitiria a comparação estatística dos dados.

No que diz respeito à influência do sexo nas concepções de adolescentes sobre o tema do envelhecimento não foram encontradas publicações sobre tal influência. Novos estudos precisam ser realizados para avaliar esta associação.

A velhice é um conceito historicamente construído que se integra ativamente à dinâmica das atitudes e dos valores culturais da sociedade. A marca social da velhice é estar em oposição à juventude. Em todas as culturas e em todos os tempos, existe forte associação entre velhice, dependência, afastamento, improdutividade, isolamento, desvalorização social, doença, incapacidade, declínio e morte. Em todos os contextos, é recorrente a oscilação entre a glorificação e a depreciação da figura do velho, a aceitação e a rejeição da velhice, o realismo e o idealismo na consideração das características da velhice e dos idosos. ${ }^{11}$

Apesar do relato acima, algumas concepções positivas apresentaram significância estatística em nossas análises, como apresentado nas tabelas 2 e 3. Pode ser que a divulgação de informações positivas sobre o envelhecer esteja influenciando positivamente as novas gerações. Entretanto, em um grande número de itens avaliados não foi possível comprovar estatisticamente uma tendência positiva ou negativa, o que comprova a afirmação da autora.

Os jovens fazem referência a uma visão mais estereotipada do envelhecimento: processo marcado pelo fim da vida produtiva, em que o idoso, com bastante sabedoria e experiência acumulada, utiliza objetos típicos, como bengalas ou cadeiras de balanço, e vive próximo da família até a morte. ${ }^{12}$

Em estudo desenvolvido em escola de ensino fundamental no município de Tapejara - RS, participaram 18 crianças da pré-escola que frequentam a instituição no turno da manhã, sendo nove meninos e nove meninas, com idade variando entre seis e sete anos de idade. Observou-se que a criança, pela convivência e diálogo com seus avós, conhece sua história de vida, resgatando-a e aprendendo a valorizar sua cultura e seus valores, pois o processo de viver e envelhecer é contínuo. ${ }^{13}$

As trocas intergeracionais podem beneficiar o idoso, ao permitir que este utilize sua experiência de vida, transmitindo o passado, sua cultura, seus valores, sua história de vida. ${ }^{12}$ Assim, os adolescentes podem construir uma concepção positiva da velhice, fortalecendo seu relacionamento com os idosos e transmitindolhes sua vitalidade e alegria, fato observado também a partir dos resultados de nossa pesquisa, em que grande parte dos jovens que conviveram com pessoas idosas possui concepções de caráter positivo para esta faixa etária. ${ }^{13}$ 
Pode-se observar que a maioria dos adolescentes afirmou já ter pensado no seu envelhecimento, sendo isto o oposto afirmado em outro estudo, segundo o qual "o jovem não se preocupa com a velhice, pois ela lhe parece distante e, portanto, não é motivo de apreensão nessa fase da vida". ${ }^{10}$

Da mesma maneira, em estudo realizado na Escola de Enfermagem da Universidade Federal do Rio Grande do Sul, com uma amostra de dez alunos de graduação dos 403 matriculados, verificou-se que, em relação à própria velhice, a maioria nunca havia pensado como esta será. Parece que o fato de não pensarem na velhice seja uma forma de não ir ao encontro dessa imagem pouco otimista. ${ }^{14}$

Esta diferença pode ser explicada pelo fato de que os adolescentes entrevistados realizaram de maneira sistemática atividades sobre o tema no ambiente escolar, o que pode ter levado a maioria a refletir sobre o próprio envelhecimento. Os adolescentes reconheceram as atividades relacionadas ao envelhecimento, o que prova que ações no ambiente escolar colaboram com a reflexão dos adolescentes sobre seu próprio envelhecimento e sobre o idoso na atualidade. A porcentagem elevada (96,4\%) de adolescentes que participaram das atividades em 2008 reforça a importância de realizar tais ações de maneira sistematizada e organizada.

As atividades realizadas na escola antes desta pesquisa vieram ao encontro da seguinte afirmação:

[...] junto ao contexto familiar temos o contexto escolar,
no qual a criança inicia suas relaçôes com o mundo. A
escola tem um papel social significativo nesse processo,
pois é um espaço que permite essa interação, por meio de
estímulo, de aprendizado, de reflexão da realidade, por
meio de trocas e das vivências compartilhadas. A escola
pode despertar a crianca para assumir uma postura
ativa perante o processo de viver e envelhecer, pois um
viver saudável resultará num envelhecer saudável. ${ }^{13}$

Esta afirmativa muito se relaciona com os resultados encontrados em nossa pesquisa, onde foi clara a visão positiva dos adolescentes após a realização de trabalhos desenvolvidos pelos professores.

Projetos intergeracionais apresentam-se como o espaço mais adequado para o estabelecimento de trocas entre as gerações; para a reflexão sobre o processo de envelhecimento; para o resgate dos aspectos positivos da longevidade; para ajudar a afastar dos jovens o medo da velhice; para desenvolver nas crianças imagens de identificação e devolver aos idosos os sonhos, os objetivos e os projetos de vida. ${ }^{2}$

Estudo desenvolvido com descendentes de origem japonesa pesquisou três faixas etárias distintas desta etnia. Um dos grupos era composto de oito idosos, imigrantes japoneses, média de idade 68 anos. O grupo de meia-idade possuía oito homens descendentes de imigrantes japoneses, média de idade de 42 anos, e o último grupo era composto de jovens, constituído de 15 voluntários universitários, média de idade de 22 anos. Para a metade dos jovens entrevistados, a velhice é uma etapa da vida que se caracteriza pela oportunidade de pensar e desenvolver ações voltadas ao crescimento pessoal, propiciando novas realizações. ${ }^{15}$

Os jovens exteriorizaram ainda, em suas manifestações, uma noção de continuidade e de autorrealização, no caso de questões de desenvolvimento. Os jovens desenvolvem uma visão crítica do tratamento dispensado ao idoso pela sociedade que, segundo eles, não assimila o significado natural da velhice. Os dados evidenciam que a geração jovem ainda atribui importância ao fato de o idoso poder desfrutar sua velhice no interior da família. ${ }^{15}$

A constatação acima nos leva a compreender como a educação em família e na escola é relevante, levando ao respeito por parte dos adolescentes aos idosos de seu convívio. É a partir da relação harmoniosa entre essas duas gerações que alcançamos uma visão positiva e otimista da pessoa idosa, passando a contribuir com toda bagagem de experiência e sabedoria para a nova geração. 
Ao aproximar os adolescentes da realidade que o idoso vivencia, é possível sensibilizá-los e estimulá-los a compreender as dificuldades vivenciadas pelos idosos. Este é um papel de pais e educadores na busca de uma sociedade em que a pessoa seja valorizada em todas as etapas da vida.

\section{CONSIDERAÇÕES FINAIS}

Os resultados demonstram que muitos adolescentes possuem percepções positivas sobre o envelhecer e que percepções negativas existem, mas com menor frequência. $\mathrm{O}$ aspecto que apresentou maior sinalização negativa em relação ao envelhecer foi a percepção do idoso como dependente. O convívio com idosos influenciou positivamente a percepção referente ao tema do companheirismo na velhice. Sexo e o convívio com idosos podem estar associados a algumas

\section{REFERÊNCIAS}

1. Ferrigno JC. A co-educação entre gerações. Revista Brasileira de Educação Física e Esportes. 2006; Suppl 5:S67-9.

2. Eiras NB, Ayres JR, Soares LCEC, Silva LV, Paulino LF. INTERGERA - Programa de estudos, eventos e pesquisas intergeracionais. Anais do $2^{\circ}$ Congresso Brasileiro de Extensão Universitária; 2004 set 12-15; Belo Horizonte (MG), Brasil. Rio de Janeiro: UERJ; 2004.

3. Both A. Escola, currículo, qualidade de vida e integração de gerações. RBCEH Revista Brasileira de Ciências do Envelhecimento Humano 2006; $3(2): 43-51$.

4. Néri AL. Envelhecer num país de jovens: significados de velho e velhice segundo brasileiros não idosos. Campinas: UNICAMP; 1991.

5. Bernieri J, Hirdes A. O preparo dos acadêmicos de enfermagem brasileiros para vivenciarem o processo morte-morrer. Texto \& contexto enfermagem / UFSC. 2007;16(1): 89-96.

6. Carpena LAB. Morte versus sentimentos: uma realidade no mundo dos acadêmicos de medicina. Rev Gaucha Enferm 2000; 21(1): 100-12. concepções, não sendo possível, entretanto, comprovar uma tendência positiva ou negativa.

Uma das limitações do estudo foi o número de adolescentes envolvidos, sendo pertinente a realizaçãodepesquisascommaiorrepresentatividade nesta faixa etária que proporcionem melhor reflexão acerca da representação social da velhice neste grupo. Outro aspecto é que os adolescentes tiveram atividades curriculares que abordaram o tema do envelhecimento, o que pode ter influenciado as respostas.

A pesquisa mostrou-se importante, pois revelou que o educador pode influenciar a imagem que o adolescente possui do envelhecimento. A partir de um trabalho intencional, baseado em conceitos, percepções e vivências do universo dos estudantes, será possível ajudar os adolescentes a construir ou fortalecer concepções positivas sobre a velhice.

7. Neri AL, Jorge MD. Atitudes e conhecimentos em relação à velhice em estudantes de graduação em educação e em saúde: subsídios ao planejamento curricular. Estud. psicol. (Natal) 2006; 23(2):127-37.

8. Heredia VBM, Casara MB, Cortelletti IA. Impactos da longevidade na família multigeracional. Revista brasileira de geriatria e gerontologia. 2007; 10 (1): 07-28.

9. Victor JF, Ximenes LB, Almeida PC, Vasconcelos FF. Perfil sociodemográfico e clínico de idosos atendidos em Unidade Básica de Saúde da Família. Acta paulista de enfermagem. [periódico online] 2009 [citado 2010 abr 05]; 22(1) [cerca de 6 p.]. Disponível em: URL: http://www.scielo.br/pdf/ape/ v22n1/a08v22n1.pdf.

10. Rocha MS, Leite MT. Envelhecimento humano: depoimentos de quatro gerações de uma mesma família. Sci Med (Porto Alegre)2004; 14(3): 231-9.

11. Neri AL, Resende M, Cachioni M. Atitudes em relação à velhice. In: Freitas EV, Py L, Néri AL F, Cançado FAX, Gorzoni ML, Rocha SN, organizadoras. Tratado de geriatria e gerontologia. Rio de Janeiro: Guanabara Koogan; 2002. p.1316-23. 
12. Wachelke JFR, Camargo BV, Hazan JV, Soares DR, Oliveira LTP, Reynaud PD. Princípios organizadores da representação social do envelhecimento: dados coletados via Internet. Estud Psicol. [periódico online] 2008 [citado 2010 abr 05]; 13(2):[cerca de 10 p.]. Disponível em: URL: http://www.scielo.br/pdf/epsic/v13n2/02.pdf

13. Mazuti C, Scortegagna, HM. Velhice e envelhecimento humano: concepções de pré- escolares do município de Tapejara - RS. RBCEH Revista Brasileira de Ciências do Envelhecimento Humano 2006; 3 (2):101-12.

14. Mancia JR, Portela VCC, Viecili R. A imagem dos acadêmicos de enfermagem acerca do próprio envelhecimento. Rev Bras Enferm. 2008; 61 (2): 221-6.

15. Pinto MEB. Velhice, dependência e cuidado: perspectiva pessoal. Londrina: Eduel; 2005.

Recebido: 05/4/2011

Revisado: 25/6/2011

Aprovado: 22/7/2011 